Published in Kirke og kultur (Norwegian)

An open, independent and long-established quarterly journal

founded in 1894 and published in Norway

Ole Jakob Løland, University of Oslo

\title{
Det evig kvinnelige i den katolske kirken
}

\section{Et kjønnsperspektiv på pave Frans}

\begin{abstract}
English)
Eight years after the election of the Argentinian Jorge Mario Bergoglio as pope in the Catholic church a pattern in Pope Francis' pontificate with regard to gender becomes discernable. First, Pope Francis disseminates genderstereotypical prejudices through an essentialist categorization of women as a group. Secondly, the Argentinian refuses to give women access both to priestly ordination and to ordination as deacons. Thirdly, Pope Francis confirms the Catholic church's construction of the so-called "gender ideology" - a rhetorical figure that has proved to be a politically effective concept, especially over the past decade.
\end{abstract}

Key words: Pope Francis, Gender Essentialism, Feminism, Women Priests, Vatican II

Ole Jakob Løland (f. 1981) o.j.loland@teologi.uio.no. PhD i teologi fra Det teologiske fakultet (TF), Universitetet i Oslo 2017. Postdoktor ved TF og førstebibliotekar ved Humsam-biblioteket, Universitetsbiblioteket (UB). Blant hans siste publikasjoner er boka Pauline Ugliness. Jacob Taubes and the Turn to Paul (Fordham University Press 2020). Postnummer: 3510 Hønefoss.

6. februar 2021 fikk enda en av Pave Frans sine avgjørelser stor oppmerksomhet i internasjonale medier. Paven hadde utnevnt den franske nonnen Nathalie Becquart til en av to nye undersekretærer for synoden av biskoper. Dermed ble Becquart den første kvinnen til å inneha embetet og dermed første kvinne som får stemmerett på synoden. Neste bispesynode er planlagt $\mathrm{i}$ 2022. ${ }^{1}$ 
Fremstillingen av utnevnelsen lot til å inngå i et mønster i mediedekningen av katolisismens globale overhode der liberalt orienterte medier til stadighet har tolket pavens ord og handlinger som tegn på en stor endring i verdens største religiøse organisasjon. En av de første biografiene om den sittende pave bar tittelen The Great Reformer, og dette bildet av argentineren som en reformator ble også et ikon for vestlig populærkultur med forsiden av magasinet Rolling Stone i 2014. Her prydet pave Frans forsiden med overskriften fra Bob Dylan's strofe: «The times they are a-changin». Magasinet betegnet latinamerikanerens pontifikat som intet mindre enn en «revolusjon». ${ }^{2}$ If $\emptyset$ lge Pew Research Center hadde pave Benedict XVI mindre medieomtale i sine åtte år enn pave Frans hadde i sitt første. ${ }^{3}$

Massemedialiseringens pave bryter ofte Vatikanets egne protokoller, viser sin folkelige varme i tilnærmingen til lekfolk og kommuniserer gjennom mediene fleksibilitet i det som har blitt oppfattet som et område hvor kirken er særlig streng: Det som har med seksualitet og familie å gjøre. ${ }^{4} \mathrm{Et}$ eksempel på det siste kom med uttalelsen på vei tilbake fra pavens verdensungdomsdager i Brasils Rio de Janeiro i juli 2013: «Hvis en person er homofil og søker Gud og har en god vilje - hvem er jeg til å dømme? $»^{5}$

Bildet av pave Frans som en stor reformator, til og med som en revolusjonær, ble konstruert og vedlikeholdt i mediene også etter at argentineren utviste det som kan betegnes som en påfallende mangel på fleksibilitet i synet på kvinners rolle i kirken. 24. november 2013 publiserte Vatikanet Bergoglios første apostoliske formaning som pave, Evangelii Gaudium. Her fastslo argentineren at ordinasjon av kvinner som prester var helt uaktuelt. At pave Frans ikke avbrøt Vatikanets etterforskning av den katolske organisasjonen Leadership Conference of Women Religious (LCWR) var også et viktig signal. Etterforskningen ble igangsatt under pave Benedikt XVI etter særlig mistanke om at organisasjonen spredte feministiske ideer som var uforenlige med katolske tro. Den kontroversielle etterforskningen ble offisielt avblåst i 2015.

For mange er spørsmålet om kvinners stilling i den katolske kirken en viktig prøvestein på om pave Frans virkelig er en pave som virkeliggjør pave Johannes XXIII sin visjon om en oppdatering av kirkens tilnærming til den moderne verden. Visjonen om aggiornamento motiverte Johannes XXIII til å kalle inn til et verdensvidt konsil som han åpnet i 1962. Konsilhistorikeren Massimo Faggioli har betegnet den teologiske tenkningen om kvinner som det viktigste spørsmålet for resepsjonen av det andre vatikankonsilet. ${ }^{6}$ Sosiologen Marco Marzano argumenterer også for at pave Frans' sitt syn på kvinners stilling er grunnleggende for hvorvidt argentinerens skal kunne betegnes som en reformpave eller ei. Marzano konkluderte i 2018 med at Bergoglio ikke har gjennomført en reform i betydningen av å ha forårsaket vesentlige strukturelle endringer av den religiøse organisasjonen han leder. Den katolske kirken virker i det store og hele ubevegelig. ${ }^{7}$

Jo lenger ut i Bergoglios pontifikat vi kommer, jo tydeligere vil man kunne observere konturene av den ideologiske og teologiske retningen som kirken har tatt under pave Frans. Så hvilken retning har den katolske kirke gått i under pave Frans når det gjelder synet på kvinner ut fra forestillinger om kjønn og seksualitet, reguleringen av kvinners funksjoner i kirken og den kirkelige retorikken om såkalt «kjønnsideologi»? Og hva slags syn på kjønn forfektet argentineren før han ble katolisismens globale overhode? 


\section{Feministisk kritikk av skrift og tradisjon}

Litteraturviteren Toril Moi har betegnet Simone de Beauvoir's Det annet kjønn fra 1949 som det tjuende århundrets viktigste feministiske tekst fordi «den gir filosofisk dybde til kvinners dagligdagse erfaringer ${ }^{8}{ }^{8}$ Beauvoir hadde bakgrunn fra en katolsk familie i Frankrike og Det annet kjønn er da heller ikke fri for referanser til autoritative fortolkningslag i den katolske tradisjonen. Allerede på første side ironiserer Beauvoir over at kvinnelighetens essens på Thomas Aquinas' tid «var like klart definert som valmuens søvndyssende virkning». ${ }^{9}$ Hun påpeker også hvordan Eva i Bibelens skapelsesfortelling av en fortolker (ved navn Bossuet) blir gestaltet som et av Adams «overflødige ribben $" .{ }^{10}$ Både skrift og tradisjon fremstilles hos Beauvoir som vesentlige kilder for at menneskeheten defineres på mannens premisser. ${ }^{11}$ Mannen er utgangspunktet, han er det første kjønn - kvinnen er det annet $\mathrm{i}$ den gudegitte rangordning. I denne idébestemte kvinneundertrykkelsen har prester og teologer alliert seg med andre intellektuelle:

Lovgivere, prester, filosofer, forfattere og lære har arbeidet iherdig for å vise at kvinnens underlegne stilling er villet i himmelen og fordelaktig på jorden. De religionene som mennene har formet gjenspeiler denne viljen til å herske: de har hentet sine våpen fra legendene om Eva og Pandora. De har tatt filosofien og teologien i sin tjeneste... ${ }^{12}$

Den feministisk motiverte religionskritikken hos Beauvoir er på denne måten rettet mot de som bruker teologien, i særlig grad den kristne, til å essensialisere kvinneligheten gjennom å befeste noe evig kvinnelig som resultat av en gudegitt og naturlig orden.

Ingen lever helt uavhengig av sitt eget kjønn. Kroppens kjønn er alltid tilstede, selv om kontekst vil avgjøre hvor viktig kjønnsdimensjonen er. Som Toril Moi fremhever i sin tolkning av Det annet kjønn: «Å si at den kjønnete kroppen er en unngåelig bakgrunn for alle våre handlinger, er det samme som å hevde på en og samme gang at kroppen alltid er en potensiell meningskilde og å benekte at den alltid er nøkkelen til å forstå en kvinnes handlinger. ${ }^{13}$

Samtidig kritiserer hun den opplysningshumanismen som avfeier relevansen av kjønn ut fra en idé om menneskers universelle likeverd. Det finnes også mer subtile former for kvinneundertrykkelse bak den angivelige tolerante opplysningshumanismen, som gjerne proklameres av demokratisk innstilte menn:

Det trengs mye selvoppofrelse for å la være å hevde seg som det eneste, absolutte. Subjekt. Det store flertallet menn kommer for øvrig ikke eksplisitt med dette kravet. De etablerer ikke kvinnen som underlegen: i dag er de altfor gjennomsyret av det demokratiske ideal til ikke å anerkjenne alle mennesker som likeverdige. ${ }^{14}$

Kjønnsforskjeller, likesom etniske forskjeller, ${ }^{15}$ fortsetter å prege menneskers liv også der hvor idealer om likeverd forfektes. Den katolske kirkens liv og lære illustrerer dette. Pave Frans viderefører en offisiell katolsk diskurs som ikke «etablerer» halve menneskeheten som underlegen, slik Beauvior fremhever. Denne diskursen er altfor preget av demokratiske ideer om likeverd til det. Like fullt dyrker pave Frans ideer om essensielle og naturgitte forskjeller mellom menn og kvinner parallelt med å begrunne menneskers adgang til presteembetet med en idé om en helt avgjørende kjønnsforskjell. Den såkalte komplementære antropologien dyrkes i katolisismen side om side med disiplinær praksis hvor kun individer som anerkjennes som menn kan tre inn i prestehierarkiet og dermed forfremmes til innflytelsesrike formelle posisjoner som biskop, kardinal og pave. ${ }^{16}$ 


\section{Pavens kjønnsessensialisme}

Som overhodet for kristenhetens desidert største kirkesamfunn regnes en pave for å være en opinionsdanner av et helt unikt kaliber i samfunn hvor katolisismen har høy oppslutning. Ingen region i verden står den så sterkt som i Latin-Amerika. Den brasilianske teologen Ivone Gebara er blant dem som har latt seg inspirere av Beauvoir og andre for å formulere et alternativ til den komplementære antropologiens kjønnspolaritet som er forankret i en antatt biologisk forskjell. ${ }^{17}$ Gebara har også observert pave Frans sine generaliseringer om kvinner og betegnet dem som infantiliserende og naive. ${ }^{18}$ De mest utbroderende generaliseringene om kvinner har Bergoglio kommet med $\mathrm{i}$ intervjuer snarere enn $\mathrm{i}$ kirkelige dokumenter.

Allerede som erkebiskop av Buenos Aires ga Bergoglio uttrykk for at kvinner har andre evner og karaktertrekk enn menn fordi de er kvinner. I en bok bestående av dialoger mellom ham selv og den argentinske rabbineren Abraham Skorka går de to gjennom ulike temaer. Innholdsfortegnelsen lister opp 29 temaer, hvor av ett er «om kvinnen». Det er betegnende for Bergoglios tilnærming til «det annet kjønn» at hans kjønnsperspektiv i liten grad berører mannen. Når han taler om kjønnsforskjeller, enten som erkebiskop eller pave, så er hovedfokus på kvinnen. Maskulinitet blir så å si aldri berørt. Kvinnelighet eller femininitet blir definert og kvinnens verdi understreket.

I dialogen fra 2010 med rabbineren Skorka forklarer Bergoglio at kvinnen har en annen funksjon i kristendommen enn mannen, som er reflektert i Jomfru Maria. Kvinnen er den som tar ansvar i samfunnet som mor for fellesskapet. Kvinnen besitter morskapets talent, samt mildhetens og hengivenhetens gave. ${ }^{19} \mathrm{Og}$ i katolsk tradisjon er Jomfruen st $\varnothing$ rre enn apostlene, understreker Bergoglio for å poengtere at kvinner ikke er mindre verdt bare fordi de ikke kan ut $\varnothing v e$ presteembetet. ${ }^{20}$

l et intervju som pave fra 2016 med forskningsdirektøren Dominique Wolton argumenterer Bergoglio igjen ut fra premisset om at kvinnen deler et generelt trekk som synes forbundet med morskapet - enten i potensiell eller faktisk forstand: «Women have this maternal capacity to unite, children argue among themselves, but the mother imposes unity. $\rangle^{21}$ Kvinner har en særlig evne som mødre til å skape enhet, ifølge paven. I et intervju med den argentinske journalisten Hernán Reyes Alcaide fra 2017 gir paven inntrykk av at røttene til slike særlige evner hos kvinner ligger i biologien. Ifølge paven er kvinnen generelt den som beskytter livet mest, fordi hun bærer det inni seg. Mannen som befrukter kvinnen og befinner seg utenfor denne sameksistensen under svangerskapet erfarer dette annerledes. Kvinnen har en egenartet form for fysisk og kroppslig hukommelse. I påfallende motsetning til Beauvoir og andre feministteoretikere, gir ikke paven eksplisitt uttrykk for at belegget for denne essensielle kjønnsforskjellen finnes i Bibelen eller i tradisjonen. Derimot hevder han at det finnes «studier» som underbygger synspunktene hans. ${ }^{22}$

Disse synspunktene har også bakgrunn i pavens egen pastorale erfaring, tilkjennegir argentineren. Når han rådfører seg med kvinner finnes «en annen visjon» som er «annerledes» og «berikende» enn hos menn. Bergoglio hevder at kvinner er mer kreative når de skal løse problemer enn det menn er. Det er også derfor han liker å blande menn og kvinner, for de komplementerer hverandres standpunkter på en god måte, understreker paven. ${ }^{23}$ Som han skriver i Evangelii Gaudium:

Kirken ved om og anerkender kvindens uundværlige bidrag til samfundet - gennem hendes særlige sensibilitet, hendes intuition, ligesom der er egenskaber og evner, der som regel findes 
mere hos kvinder end hos mænd. For eksempel den særlige kvindelige opmærksomhed over

for andre, som finder sit specielle udtryk i moderskabet - om end ikke udelukkende dér. ${ }^{24}$

Kvinnen i entall har en spesiell følsomhet og intuisjon som ikke finnes hos menn i samme grad, ifølge paven. På denne måten har Bergoglio kommet på sporet av «det evig kvinnelige» som Beauvoir ironiserte over og dekonstruerte. Der Beauvoir motarbeidet og kritiserte essensialismen om kvinner, bidrar paven til å forsterke og utbre den. Det skal sies at paven sjelden har uttalt seg om spesifikke kvinnesaksforkjempere og kjønnsteoretikere. Men i samtalen med Skorka kritiserer han «feminismen» når den regnes som «den eneste filosofi». Uten at det er klart hva slags type feminisme det dreier seg om, kritiserer Bergoglio feministene for å svikte kvinnene de hevder å representere. Ifølge Bergoglio fører de kvinnene inn i en kamp for å kreve mer («lucha reivindicativa») og «kvinnen er mye mer» enn denne kampen. En feministfilosofi som konstant kjemper for mer og mer gir ikke den verdigheten som kvinnen fortjener, hevder argentineren, før han varsler at han skal karikere feministene litt og uttaler: «De løper risikoen med å bli til en machismo med skjørt. ${ }^{25}$ Dette uttrykket har Bergoglio anvendt gjentatte ganger som pave i kontekster hvor kvinners stilling i kirken har stått på dagsorden, blant annet på det internasjonale toppmøtet i Vatikanet i februar 2019 om overgrepskrisen.

Det spanske ordet «machismo» brukes i latinamerikanske studier om «forestillingen om mannlig overlegenhet og rett til å dominere kvinner, samt en legitimering og naturalisering av mannlig aggresjon og virilitet på den ene siden og kvinners servilitet og seksuelle kyskhet på den andre siden $" .{ }^{26}$ Når Bergoglio bruker begrepet om en vag feministisk posisjon som han vil bekjempe spiller han derfor på en form for mannssjåvinisme som av mange regnes som typisk for Latin-Amerika. Det er derfor et retorisk grep for å svartmale motstanderens posisjon, som om feministene gjør noe like ille som mannssjåvinistene, men med motsatt fortegn. ${ }^{27}$

Når en feminist i det hele tatt er et motiv i pavens diskurs som en meningsmotstander bør det leses på bakgrunn av hans argentinske kontekst. Landet har de siste tiårene sett noen av regionens sterkeste feministbevegelser. Etter at Argentina ble en pioner for å sikre rettigheter for seksuelle minoriteter med å legalisere likekjønnet ekteskap i 2010 (pluss en lov juridisk rett til et tredje kjønn i 2012), ${ }^{28}$ mobiliserte i særlig grad feministbevegelser for legalisering av abort. Bergoglio ledet an kampen mot en oppmykning av abortlovgivningen på vegne av den katolske kirken som erkebiskop av Buenos Aires fra 1998 til 2013, men måtte fra pavestolen konstatere at kampen var tapt med den argentinske kongressens vedtak om avkriminalisering i desember 2020. Feministene og deres brede støtte i Argentina hadde triumfert politisk over den katolske kirken.

\section{Midlertidige oppdrag for kvinner og permanente posisjoner for menn}

Nathalie Becquart sitter i en innflytelsesrik posisjon på pavens nåde. Hun innehar ingen permanent posisjon, slik for eksempel en mannlig biskop normalt sett har. Becquart har vært rådgiver for Vatikanet siden 2019, men som første kvinne får hun nå stemmerett på bispesynoden. Den posisjonen svarer ikke på kravet som har blitt reist fra mange kvinner i den katolske kirken, i særlig grad fra USA, om at også kvinner bør få adgang til presteembetet. Men det kan forstås som en imøtekommelse av et bredere krav blant et større antall katolikker om mer innflytelse for kvinner $\mathrm{i}$ kirkens beslutningsprosesser - et krav som kan reises uavhengig av spørsmålet om kvinner og 
presteordinasjon. Nathalie Becquart mener til eksempel ikke at adgang til presteembetet for kvinnene er det viktigste spørsmålet for kvinners plass i kirken. ${ }^{29}$ Slik sett er hun på linje med, i det minste ikke i konlikt med, pave Frans sitt syn. Allerede i sin første apostoliske formaning la pave Frans debatten om kvinnelige prester i den katolske kirken i løpet av sitt pontifikat $d \varnothing d$. Her stadfestet paven det som teologen Kari Elisabeth Børresen (1932-2016) betegnet som «kvinners kultiske kjønnshindring»: ${ }^{30}$

Hævdelsen af kvinders legitime rettigheder, baseret på den faste overbevisning om mænds og kvinders lige værdighed, konfronterer Kirken med dybtgående spørgsmål, der betyder udfordringer - spørgsmål, man ikke blot overfladisk kan slippe uden om. At det særlige præsted $\varnothing$ mme er forbeholdt mænd som et tegn på Kristus som brudgommen, der hengiver sig selv i eukaristien - dét er et spørgsmål, der ikke er til diskussion, men det kan give anledning til en særlig konflikt, hvis man i for høj grad sætter lighedstegn mellem sakramental myndighed og magt i det hele taget. ${ }^{31}$

Paven er preget av det demokratiske ideal i den forstand Beauvoir talte om. Han forsvarer menn og kvinners likeverd og tar til ordet for kvinnens rettigheter. Spørsmålet er likevel om det ikke er en abstrakt likestilling all den tid likeverdstanken sammenstilles i pavens teologi med kjønnsdiskriminering. Kvinnen kan ikke bli ordinert som prest ene og alene på grunn av sitt kjønn, et syn de som hadde fulgt Bergoglio i Argentina ikke ble forbauset over. I den nevnte dialogen med rabbineren Skorka kom det eksplisitt frem at Bergoglio forsvarte en konvensjonelt syn $\mathrm{i}$ kvinneprestspørsmålet og begrunnelsen om at presteordinasjon var basert på Jesu kjønn. ${ }^{32}$ At tilhengere av presteordinasjon i den katolske kirken peker på Jesu menneskelighet snarere enn kjønn, der Jesus ifølge den kalkedonske formuleringen av inkarnasjonen tar opp i seg den hele og fulle menneskelige natur, ${ }^{33}$ er ikke noe Bergoglio verken som biskop eller pave har hatt behov for å imøtegå. Han har derimot hatt behov for å tydeliggjøre at ordinasjon av kvinner ikke er et spørsmål som er til diskusjon. Derimot har han vært åpen for å drøfte muligheten for at kvinner kan ordineres som diakoner, et spørsmål som siden konsilet har vært mindre kontroversielt og mer aktuelt. ${ }^{34} \mathrm{I}$ et intervju fra 2016 holdt paven fortsatt muligheten åpen:

There's a real dynamism in women and women's qualities. Some women say to me, "Why can't we become deaconesses?" And that's an office. We can think about that. ${ }^{35}$

På bakgrunn av det medieskapte bildet av en reformpave, pavens opprettelse av en kommisjon for studiet av spørsmålet i 2016 og denne typen formuleringer var forventningene store etter bispesynoden om Amazonas i oktober 2019. Det var ikke minst fordi kvinners rolle var et sentralt tema i arbeidsdokumentet for synoden. I sitt sluttdokument erklærte de 185 synodefedrene at spørsmålet om kvinnelige diakoner hadde vært gjenstand for stor interesse. Men da pave Frans publiserte sin apostoliske formaning Querida Amazonia i februar 2020, som svar på bispesynoden, var også det spørsmålet tilsynelatende lagt dødt eller satt på vent - antakelig ut hele argentinerens pontifikat.

Formaningen vektlegger kvinners betydning i Amazonas. De har døpt, drevet trosopplæring og virket som misjonærer i regionen, skriver pave Frans. Gjennom hundreårene har kvinner holdt liv i kirken gjennom sin dype tro. Dette utvider perspektivet, ifølge paven, med mindre man reduserer forståelsen av kirken til funksjonsmessige og strukturelle spørsmål. Dette er for paven en reduksjonisme som leder en til å tro at kvinners styrkede deltakelse i kirken er avhengig av deres 
adgang til sakramentale embeter. Dette vil lede til en klerikalisering av kvinner, advarer pave Frans. 36

Fra starten av sitt virke har pave Frans gjort kritikken av «klerikalisme» til ett av hovedtemaene i sine taler. Like fullt lot paven spørsmålet om hva som er verre med en klerikalisering av kvinner enn menn, som hans argument inviterer til, stå ubesvart. Dernest forutsetter paven igjen at kvinner har distinkte karakteristika som kvinner. Verdien av det kvinner har oppnådd i kirken vil reduseres hvis de havner i posisjoner hvor de risikerer å bli ofre eller agenter for en $\varnothing$ deleggende klerikalisme. Kvinnens essensielle kvaliteter synes for paven å henge sammen med at det sakramentale embetet $\mathrm{i}$ kirken forbeholdes menn. Det ene forringes uten det andre. Med andre ord idealiserer pave Frans kvinnen og denne idealiseringen fungerer delvis som et argument for at kvinner ikke skal ordineres til diakoner og prester. Samtidig er det et interessant trekk ved pavens retoriske strategi $\mathrm{i}$ å betone faren for «klerikalisering» av kvinner: Det fungerer uten å appellere til skrift eller tradisjon. Uten en utbroderende teologisk begrunnelse unngår paven å invitere til teologisk sterke motargumenter, som er en del av katolske feministteologers retoriske arsenal.

Teologen Sally Vance-Trembath er blant dem som hevder at det andre vatikankonsilets konklusjoner ikke har blitt anvendt på kvinners stilling i kirken. Det er et gap mellom konsiltekstenes rikdom og den manglende implementeringen i den katolske kirkens faktiske liv, hevder Vance-Trembath uten å tematisere kvinneprestspørsmålet eller ta stilling til hvilke formelle posisjoner kvinner burde få komme inn $i^{37}$ Det kan være politiske og strategiske grunner til at hun ikke tematiserer dette og $\mathrm{i}$ stedet legger vekt på kirken ikke trenger noe nytt konsil eller en ny teologi for å gi kvinner deres rettmessige plass.

\section{Til kamp mot kjønnsideologi}

Bak begrepet «kjønnsideologi» ligger det svake konsepter og mektig politikk, har litteraturviteren Agnieszka Graff hevdet. ${ }^{38}$ Katolisismens kjerneområde Latin-Amerika har på 2000-tallet vært den kanskje viktigste politiske kamparenaen globalt sett for kjønn og seksuelle minoriteter. Bortsett fra Nord-Europa og USA har ingen region i verden sett en raskere utvidelse av LGBT-rettigheter enn Latin-Amerika. ${ }^{39}$ I det landet i verden med flest katolikker ble Jair Messias Bolsonaro innsatt som president 1. januar 2019. I sin innsettelsestale lovet Bolsonaro å frigjøre Brasil fra ideologisk undertrykkelse og bekjempe «kjønnsideologi». ${ }^{40} \mathrm{Kj} ø n n$ og seksualitet hadde stått sentralt i en valgkamp hvor Bolsonaros motkandidat, Fernando Haddad, ble anklaget for å ville oppdra barn til å bli homofile og lesbiske som et ledd $i$ en fordekt strategi fra en «kulturmarxistisk» elite som vil spre «kjønnsideologi». I Latin-Amerika har «kjønnsideologi» blitt et kraftfullt politisk slagord som spilte en viktig og muligens avgjørende rolle i politiske begivenheter som Bolsonaros valgseier i 2018 og et nei til fredsavtalen mellom FARC-geriljaen og regjeringen i Colombia i en folkeavstemning i $2016 .{ }^{41}$ Avtaleteksten ble ansett av mange colombianere for å fremme «kjønnsidelogien» - et begrep som for første gang ble brukt i et offisielt katolsk dokument i regionen i 1998 (av den peruanske bispekonferansen). ${ }^{42}$ Under Bergoglios ledelse kom det inn i konklusjonene fra den latinamerikanske bispekonferansen i 2007 da argentineren ledet redigeringen av dokumentene i sluttfasen av biskopenes drøftinger. ${ }^{43}$ 
I lys av begrepets omstridte virkningshistorie i latinamerikansk politikk kunne historiens første pave fra regionen har valgt å tematisere kjønn og seksualitet uten å anvende begrepet. Pave Frans valgte likevel å bruke begrepet, og dermed også bekrefte dets teologisk-politiske legitimitet gjennom å holde fast ved det i prekener og i den postsynodale apostoliske formaningen Amoris Laetitia fra 2016. I prekener har paven også valgt en retorikk som er påfallende lik Bolsonaros argumentasjon: På sine reiser til blant annet Filippinene, Georgia og Polen har pave Frans hevdet at «kjønnsideologien» påtvinges mennesker av i dag gjennom «ideologisk indoktrinering» og «ideologisk kolonisering». ${ }^{44}$

| Amoris Laetitia anvendte paven begrepet «kjønnsideologi» for å angi farene som truer familien og fører til identitetsmessig rotløshet og familiens oppløsning. Og han holdt fast ved at det er én ideologi som er på ferde, som om det er en enhetlig idémessig størrelse. Samtidig fastholdes mønsteret i pontifikale dokumenter med å usynliggjøre både kjønnsteoretikere generelt og feministteologer spesielt. Ingen av de mange bidragene innenfor katolsk feministteologi siteres og pavens refleksjoner om kjønn signaliserer snarere en avvisningen enn åpenhet for dialog med vitenskapene om temaet. ${ }^{45}$

I formaningen fra 2016 advarer pave Frans mot ideologien fordi den leder til utdanningsprogrammer (jmfr. anklagen mot Bolsonaros motkandidat) og lover (jmfr. den argentinske loven om det tredje kjønn i Argentina) som promoterer personlig identitet og følelsesmessige bånd som er radikalt atskilt fra «den biologiske forskjellen mellom mann og kvinne» - uten å spesifisere nærmere hva denne forskjellen skulle bestå i. Det er like fullt nærliggende å forstå pavens formuleringer på bakgrunn av hans erfaringer med innføringen av likekjønnet ekteskap i hans hjemland og krav om homofile og lesbiskes rettigheter. Som paven uttalte i et intervju i 2018:

What should we think about same-sex marriage? "Marriage" is a historical word. Forever, throughout humanity, and not only in the Church, it's between a man and a woman. You can't change it just like that. It's the nature of things. That's how they are. So let's call them "civil unions". Don't let's joke with the truths. It's true that, behind it, there is the ideology of gender. In books, too, children learn that they can choose their sex. Why gender, being a woman and a man, is a choice and not a fact of nature? That favors this error. ${ }^{46}$

Paven fastslår at ordet «ekteskap» skal forbeholdes en heteroseksuell relasjon, mens homoseksualitet også trenger sivilrettslige rammer. Ekteskapets særskilte status begrunner paven i en vag forestilling om en universell historie, samt en naturgitt orden mellom mann og kvinne som ikke bare finnes i kirken. Problemet er synet om at barnet kan velge sin seksuelle tilbøyelighet eller natur, hvilket later til å være kvintessensen av hva pave Frans forstår som «kjønnsideologi». Dermed forledes mennesker til å tro at de kan benekte eller fri seg fra sin naturgitte seksualitet som mann eller kvinne. Kjønnspolariteten er her absolutt - det finnes ingen gråsoner eller kategorier mellom det ene eller det andre kjønnet.

Samtidig er ikke pave Frans helt koherent i Amoris Laetitia når han siterer synodefedrene fra 2015 på at "biological sex and the socio-cultural role of sex (gender) can be distinguished but not separated" ${ }^{47} \mathrm{Her}$ åpner paven for en differensiering mellom en biologisk programmert seksualitet (sex) og et sosialt konstruert kjønn (gender) som han både utelukker og unnlater å reflektere over $\mathrm{i}$ andre taler, intervjuer og skrifter - for eksempel i den berømte encyklikaen Laudato Si fra $2015 .{ }^{48}$ Den fikk mye oppmerksomhet for sin åpenhet for $\varnothing$ kologisk tenkning og naturvitenskapelige 
innsikter, men færre la merke til hvordan skriftet insisterte på en statisk kjønnspolaritet og en kjønnsforskjell som en epistemologisk forutsetning for å erfare annerledeshet:

Det er [...] å verdsette kroppen i dens maskulinitet eller feminitet, for å kunne gjenkjenne seg selv i møtet med den som er annerledes. Slik kan vi med glede ta imot den andre, mannen eller kvinnen, som en gave, som Gud Skaperens verk, og bli gjensidig beriket. Det er derfor ingen sunn holdning å søke å utslette forskjellen mellom kjønnene fordi man ikke lenger vet å forholde seg til den. ${ }^{49}$

Det er interessant å observere at når det skjer teologisk nyskapning på andre områder under pave Frans' pontifikat så forblir synet på kjønn og seksualitet uforandret. Bergoglio overtar simpelthen Ratzinger og Wojtylas teoretiske forutsetninger. Forgjengernes tanke om komplementaritet mellom mann og kvinne innarbeides som grunnlag for den nye økoteologien som kommer til uttrykk i Laudato Si. ${ }^{50}$ Kroppen skal verdsettes i sin «maskulinitet eller feminitet» og tydeligvis ikke begge samtidig eller litt av det ene og litt av det andre. Og det er kroppen som er enten maskulin eller feminin - ikke våre sosiale konstruksjoner av den. På den måten vil vi ifølge pave Frans virkeliggjøre "en etik, der ikke er gjort til ideologi». ${ }^{51}$ Det er med andre ord en vei ut av kjønnsideologien - en etisk sfære fri for all form for ideologi - der naturens gudgitte orden i menneskene er verdsatt $\mathrm{i}$ enten sin maskulinitet eller feminitet.

\section{Konklusjon}

Feministteologer som norske Kari Elisabeth Børresen til brasilianske Ivone Gebara har begge påpekt at den katolske kirkens offisielle teologi er premoderne i sin tilnærming til sex og kjønn. ${ }^{52}$ Verdens største kirkesamfunn er i påfallende grad uvillig til å gå inn i samtidens kjønnsteoretiske debatter og la sin teologi bli aktualisert og kontekstualisert av dem. Med unntak av en liten åpning i sitatet fra synodefedrene i Amoris Laetitia står pave Frans fast på at naturlige komplementære kjønnsforskjeller finnes og at sosiale forestillinger om en viss individuell frihet $\mathrm{i}$ forhold til kjønnsidentitet er falske. De er produkter av kjønnsideologiens ideologiske kolonisering og indoktrinering som i særlig grad rammer barn. Kjønn er ikke, som Judith Butler ville sagt, «en identitet som forsiktig blir konstruert $i$ tiden, etablert $i$ et ytre rom gjennom en stilisert gjentakelse av handlinger».$^{53}$ Snarere enn konstruert er kjønn noe som for pave Frans kommer av en naturgitt seksualitet som er enten iboende mannlig eller kvinnelig - helt og fullt.

Spørsmålet om kvinnelige prester er definitivt ikke oppe til debatt under pave Frans sitt teologiskpolitiske regime. Det er sannsynligvis heller ikke spørsmål om et permanent diakonat for kvinner. I den grad kvinner skal ha betydelig makt på kirkens avgjørelser er det gjennom midlertidige og ikke permanente posisjoner. Mannen har en funksjonell forrang i kulten som pave Frans egentlig begrunner i sin forestilling om frelseshistorien: Gud valgte å bli menneske gjennom å ta bolig i en mann. Kvinner og menn har lik verdi, men ulike funksjoner. Å ville gi kvinner like funksjoner som menn er ifølge paven å gjøre kvinner til ofre for klerikalisering og redusere verdien av de naturgitte dydene som kvinner i særlig grad virkeliggjør i samfunnet. I tillegg ville et slikt grep være uttrykk for en «machismo med skjørt» - en kvinnesjåvinisme.

Åtte år har gått siden Jorge Mario Bergoglio ble valgt til pave. Et mønster i pave Frans' tilnærming til kjønn avtegner seg: For det første sprer pave Frans kjønnsstereotypiske fordommer med en 
essensialistisk kategorisering av kvinner som gruppe. For det andre stenger pave Frans adgangen for kvinner til både presteordinasjon og diakonordinasjon. For det tredje bekrefter pave Frans den katolske kirkes konstruksjon av såkalt «kjønnsideologi» - en retorisk figur som har vist seg som et politisk effektivt begrep, spesielt det siste tiåret.

Reformiveren i den katolske kirken i tiårene etter det andre vatikankonsilet, spesielt i form av kravet om kvinners kultiske likestilling, var inspirert av konsiltekster som hadde en dialogisk og forsonende tone med moderniteten - etter over hundre år med katolsk antimodernisme. En slik iver hentet legitimitet i konsiltekster som Gaudium et spes:

I dag har menneskeheten nådd en etappe i sin utvikling, som kjennetegnes ved at dyptgripende og hurtige forandringer brer over hele jorden. Disse forandringer skyldes menneskehetens forstand og skapende evne, men de virker også tilbake på mennesket, på dets individuelle så vel som kollektive vurderinger og behov, på dets tenke- og handlemåte overfor både ting og medmennesker. Vi kan derfor allerede nå tale om en virkelig sosial og kulturell forvandling som også påvirker det religiøse liv. ${ }^{54}$

For mange mennesker er moderne feminisme, likestilling og seksuell frigjøring noen av de mest dyptgripende kulturelle endringene som har skjedd i verden det siste hundreåret. Det burde derfor reflekteres i teologien som regulerer det religiøse liv i den katolske kirken. For andre er disse kulturelle endringene snarere beviset på at konsilfedrene gikk for langt i sin positive tilnærming til de raske og moderne samfunnsendringene som bredte seg over hele kloden. Til forskjell fra pave Benedikt XVI er ikke pave Frans en som eksplisitt advarer mot at konsiltekstene feiltolkes av dem som ivrer for reform i den katolske kirken. Argentineren virker mindre urolig for forståelsen av dokumentene. Like fullt foregår det en konstant dragkamp om tolkningen av konsiltekstene - særlig i forhold til kjønn. Det andre vatikankonsilet kan forstås som endestasjon som i sin reformiver til tider skled ut av kurs. Men det kan også forstås som et utgangspunkt for ytterligere aggiornamento som kirken ennå ikke har tatt konsekvensene av.

\section{Litteraturliste}

Amaya, José Fernando Serrano. «La tormenta perfecta: Ideología de género y articulación de públicos.». Sexualidad, Salud y Sociedad. Revista Latinoamericana, nr. 27 (2017): 149-171. https://doi.org/10.1590/1984-6487.sess.2017.27.09.a

Bastante, Jesús. «Nathalie Becquart: "En la Iglesia clerical que heredamos, las mujeres no son escuchadas. Esto debe cambiar".» Religión Digital 08.04.2021. https://www.religiondigital.org/vaticano/NATHALIEBECQUART-mujeres-igualdad-democracia-vaticano-sinodalidad-iglesia-laicosclericalismo_0_2327767237.html.

BBC. «Pope Francis: Who am I to judge gay people?» BBC News 29.07.2013. https://www.bbc.com/news/world-europe-23489702.

Beauvoir, Simone de. Det annet kjønn. Oversatt av Bente Christensen. Bokklubbbens kulturbibliotek. Oslo: De norske bokklubbene, 2000.

Bergoglio, Jorge Mario, og Abraham Skorka. Sobre el cielo y la tierra. Buenos Aires: Vintage Español, 2010. Bolsonaro, Jair Messias. «Discurso do Presidente da República, Jair Bolsonaro, durante Cerimônia de Posse no Congresso Nacional.» http://www2.planalto.gov.br/acompanhe-o-planalto/discursos/2019/discursodo-presidente-da-republica-jair-bolsonaro-durante-cerimonia-de-posse-no-congresso-nacional.

Butler, Judith. Kjønn, performativitet og sårbarhet. Oversatt av Lars Holm-Hansen. Cappelens upopulære skrifter. 1. utgave. Oslo: Cappelen Damm, 2020. 
Børresen, Kari Elisabeth. «Moderne maktkamp mellom pave og konsil.». Teologisk tidsskrift 4, nr. 2 (2016): 135-152. https://doi.org/10.18261/issn.1893-0271-2016-02-03

Case, Mary Anne. "The Role of the Popes in the Invention of Complementarity and the Vatican's Anathematization of Gender.» Religion \& Gender 6, nr. 2 (2016): 155-172. https://doi.org/10.18352/rg.10124

Coelho, Fernanda Marina Feitosa, og Naira Pinheiro dos Santos. «A mobilizacão católica contra a "ideologia de gênero" nas tramiacôes do plano nacional de educacâo brasileiro.». Religare 13, nr. 1 (2016): 27-48. https://doi.org/10.15603/2176-0985/mandragora.v23n2p247-279

Corrales, Javier. "Understanding the Uneven Spread of LGBT rights in Latin America and the Caribbean, 19992013.». Journal of Research in Gender Studies 7, nr. 1 (2017): 52-82. https://doi.org/10.18352/erlacs.10126

Det andre vatikankonsilet. "Pastoralkonstitusjon om Kirken i verden av i dag - Gaudium et spes.». I Det Annet vatikankonsil. Dokumenter, redigert av Fredrik Hansen, 501-612. Oslo: St. Olav forlag, 2013.

Díaz, María Constanza, Victoria Keller, Constanza Tabbush, og Catalina Trebisacce. «LGBT Rights Yes.». I Seeking rights from the Left: Gender, Sexuality, and the Latin American Pink Tide, redigert av Elisabeth Jay Friedman, 82-114. Durham: Duke University Press, 2019.

Faggioli, Massimo. A Council for the Global Church: Receiving Vatican II in History. Minneapolis: Fortress Press, 2015.

Frans, Pave. «Amoris Laetitia.» https://www.vatican.va/content/dam/francesco/pdf/apost_exhortations/documents/papafrancesco_esortazione-ap_20160319_amoris-laetitia_en.pdf.

- - - Encyklikaen Laudato Si'. Om omsorgen for vårt felles hjem. Oversatt av Anne Bente Hadland. Oslo: St. Olav forlag, 2015

- - . Evangeliets glæde. Apostolsk skrivelse fra pave Frans. København: Ansgarsstiftelsens forlag, 2014.

- - - "Querida Amazonia.» http://www.vatican.va/content/francesco/en/apost_exhortations/documents/papafrancesco_esortazione-ap_20200202_querida-amazonia.html.

Frans, Pave, og Dominique Wolton. A Future of Faith: the Path of Change in Politics and Society. New York: St. Martin's Press, 2018.

Gebara, Ivone. «Laudato Si: Algunos desafíos teológicos para una mejor convivencia en el planeta.» Alianza Biodiversidad, https://www.biodiversidadla.org/Documentos/Laudato_Si_algunos_desafios_teologicos_para_una_ mejor_convivencia_en_el_planeta. Lastet ned 11.05.21.

- - - Out of the Depths: Women's Experience of Evil and Salvation. Minneapolis: Fortress Press, 2002.

Graff, Agnieszka. «'Gender Ideology': Weak Concepts, Powerful Politics.». Religion \& gender 2016, nr. 2 (2016): 268-272. https://doi.org/10.18352/rg.10177

Larraquy, Marcelo. Código Francisco : cómo el Papa se transformó en el principal líder político global y cuál es su estrategia para cambiar el mundo. Barcelona: Debate, 2016.

Martín, Eloísa. «God is Argentine and so is the Pope! Catholicism, Popular Culture and the National Imagination.». I Religions, Nations, and Transnationalism in Multiple Modernities, redigert av Patrick Michel, Adam Possamai og Bryan S Turner, 175-195. NewYork: Palgrave Macmillan, 2017.

Marzano, Marco. La Chiesa immobile: Francesco e la rivoluzione mancata. Roma: Laterza \& Figli, 2018.

Moi, Toril. «Innledning.» Oversatt av Bente Christensen. I Det annet kjønn, redigert av Simone de Beauvoir. Bokklubbens kulturbibliotek. Oslo: De norske bokklubbene, 2000.

- - - Jeg er en kvinne. Det personlige og det filosofiske. Oslo: Pax, 2001.

Reyes Alcaide, Hernán. Papa Francisco. Latinoamérica: conversaciones con Hernán Reyes Alcaide. Buenos Aires: Planeta, 2017.

Ruyter, Knut W. «Jorden gråter og de fattige roper.». Kirke og kultur, nr. 4 (2020): 297-313.

See, The Holy. "In-flight Press Conference of His Holiness Pope Francis from the Philippines to Rome.» http://www.vatican.va/content/francesco/en/speeches/2015/january/documents/papafrancesco_20150119_srilanka-filippine-conferenza-stampa.html.

- - - «In-flight Press Conference of His Holiness to Pope Francis from Azerbaijan to Rome.» http://www.vatican.va/content/francesco/en/speeches/2016/october/documents/papafrancesco_20161002_georgia-azerbaijan-conferenza-stampa.html.

- - - «Meeting with the Polish Bishops. Address of his Holiness Pope Francis.» http://www.vatican.va/content/francesco/en/speeches/2016/july/documents/papafrancesco_20160727_polonia-vescovi.html. 
Stone, Rolling. «Pope Francis' Gentle Revolution: Inside Rolling Stone's New Issue.» Rolling Stone 28.01.2014. https://www.rollingstone.com/culture/culture-news/pope-francis-gentle-revolution-inside-rollingstones-new-issue-49840/.

Strønen, Iselin Åsedotter. «En feministisk revolusjon? Kvinner, kvinnekamp og aktivisme i Chávez’ Venezuela.». Norsk antropologisk tidsskrift 24, nr. 1 (2013): 39-51. https://doi.org/10.18261/issn1504-2898-201301-04

Sölle, Dorothee. Great Women of the Bible in Art and Literature. Grand Rapids: Eerdmans, 1994.

Toldy, Teresa. "Someone is Missing in the Common House. The Empty Place of Women in the Encyclical Letter 'Laudatio si'.». Journal of the European Society of Women in Theological Research 25 (2017): 167-189.

Vance-Trembath, Sally. "Women and Vatican II. Theological Excavations and Soundings.» I From Vatican II to Pope Francis: Charting a Catholic Future, redigert av Paul Crowley Maryknoll: Orbis, 2014.

Zagano, Phyllis. Women deacons? Essays with Answers. Collegeville: Liturgical Press, 2016.

\footnotetext{
${ }^{1}$ En stor takk til Tarjei Solvang Tjønn for opprettelsen av en liten database med utmerkede søkemuligheter i det corpus som pavens taler og skrifter utgjør.

2 Rolling Stone, "Pope Francis' Gentle Revolution: Inside Rolling Stone's New Issue,"

https://www.rollingstone.com/culture/culture-news/pope-francis-gentle-revolution-inside-rolling-stones-newissue-49840/.

${ }^{3}$ Eloísa Martín, «God is Argentine and so is the Pope! Catholicism, Popular Culture and the National Imagination," i Religions, Nations, and Transnationalism in Multiple Modernities, red. Patrick Michel, Adam Possamai, og Bryan S Turner (NewYork: Palgrave Macmillan, 2017), 175.

${ }^{4}$ Ibid., 181-182.

${ }^{5}$ Oversatt til norsk fra BBC, «Pope Francis: Who am I to judge gay people?,» https://www.bbc.com/news/world-europe-23489702.

${ }^{6}$ Massimo Faggioli, A Council for the Global Church: Receiving Vatican II in History (Minneapolis: Fortress Press, 2015), 263-264.

${ }^{7}$ Marco Marzano, La Chiesa immobile : Francesco e la rivoluzione mancata (Roma: Laterza \& Figli, 2018).

${ }^{8}$ Toril Moi, «Innledning,» i Det annet kjønn, red. Simone de Beauvoir, Bokklubbens kulturbibliotek (Oslo: De norske bokklubbene, 2000), ix.

${ }^{9}$ Simone de Beauvoir, Det annet kjønn, overs. Bente Christensen, Bokklubbbens kulturbibliotek (Oslo: De norske bokklubbe, 2000), 5.

${ }^{10}$ Muligens den franske katolske biskopen Jacques Bénigne Bossuet (1681-1704).

${ }^{11}$ De Beauvoir er også snar med å vise til andre stemmer i fortolkningshistorien som har vist til et annet og mindre kvinneundertrykkende meningspotensiale i Skapelsesberetningen: «... tvert imot, har andre sagt, Adam var bare en skisse, og Gud lyktes med et perfekt menneskelig vesen da hun skapte Eva.» Beauvoir, Det annet kjønn, 16. Eller sagt med teologen Dorothee Sölle: "Without Eve, we all would still be sitting under trees, innocently dreaming. Dorothee Sölle, Great Women of the Bible in Art and Literature (Grand Rapids: Eerdmans, 1994), 14.

12 Beauvoir, Det annet kjønn, 12-13.

${ }^{13}$ Toril Moi, Jeg er en kvinne : det personlige og det filosofiske (Oslo: Pax, 2001), 99.

14 Beauvoir, Det annet kjønn, 15.

${ }^{15}$ Beauvoir foregriper aspekter ved senere teorier om interseksjonalitet når hun tidlig i verket sitt introduserer triaden «kvinnen, jøden og den sorte». Ibid., 6.

${ }^{16}$ Teoretisk sett kan kvinner riktig nok utnevnes til medlemmer i kardinalkollegiet. Om komplementær antropologi og de siste tiårenes pavedømme se Mary Anne Case, «The Role of the Popes in the Invention of Complementarity and the Vatican's Anathematization of Gender, " Religion \& Gender 6, no. 2 (2016).

${ }^{17}$ Ivone Gebara, Out of the Depths: Women's Experience of Evil and Salvation (Minneapolis: Fortress Press, 2002), 61-66.

18 "Laudato Si: Algunos desafíos teológicos para una mejor convivencia en el planeta,» Alianza Biodiversidad, https://www.biodiversidadla.org/Documentos/Laudato_Si_algunos_desafios_teologicos_para_una_mejor_co nvivencia_en_el_planeta.
} 
${ }^{19}$ Jorge Mario Bergoglio og Abraham Skorka, Sobre el cielo y la tierra (Buenos Aires: Vintage Español, 2010), 101.

${ }^{20} \mathrm{lbid}$.

${ }^{21}$ Pope Francis og Dominique Wolton, A Future of Faith: the Path of Change in Politics and Society (New York:

St. Martin's Press, 2018), 92-93.

${ }^{22}$ Hernán Reyes Alcaide, Papa Francisco. Latinoamérica: conversaciones con Hernán Reyes Alcaide (Buenos

Aires: Planeta, 2017), 45.

23 Ibid., 46.

${ }^{24}$ Pave Frans, Evangeliets glæde. Apostolsk skrivelse fra pave Frans, (København: Ansgarsstiftelsens forlag, 2014). 55.

${ }^{25}$ Bergoglio og Skorka, Sobre el cielo y la tierra, 102.

${ }^{26}$ Iselin Åsedotter Strønen, «En feministisk revolusjon? Kvinner, kvinnekamp og aktivisme i Chávez'

Venezuela," Norsk antropologisk tidsskrift 24, no. 1 (2013): 40.

27 "[M]achismo is a brutality, a negative thing. "Machismo in a skirt" is the same thing. It doesn't represent what women must represent in society." Francis og Wolton, A Future of Faith: the Path of Change in Politics and Society, 93.

${ }^{28}$ María Constanza Díaz et al., "LGBT Rights Yes, » i Seeking Rights from the Left: Gender, Sexuality, and the Latin American Pink Tide, red. Elisabeth Jay Friedman (Durham: Duke University Press, 2019).

${ }^{29}$ Religion Digital, «Nathalie Becquart: "En la Iglesia clerical que heredamos, las mujeres no son escuchadas. Esto debe cambiar",» https://www.religiondigital.org/vaticano/NATHALIE-BECQUART-mujeres-igualdaddemocracia-vaticano-sinodalidad-iglesia-laicos-clericalismo_0_2327767237.html.

${ }^{30}$ Kari Elisabeth Børresen, «Moderne maktkamp mellom pave og konsil,» Teologisk tidsskrift 4, no. 2 (2016): 149.

${ }^{31}$ Frans, Evangeliets glæde. Apostolsk skrivelse fra pave Frans. 56.

32 Bergoglio og Skorka, Sobre el cielo y la tierra, 101.

${ }^{33}$ Sally Vance-Trembath, "Women and Vatican II. Theological Excavations and Soundings,", red. Paul Crowley, From Vatican II to Pope Francis: Charting a Catholic Future (Maryknoll: Orbis, 2014). 28. Også påpekt av Børresen, «Moderne maktkamp mellom pave og konsil,» 149.

${ }^{34}$ Phyllis Zagano, Women deacons? Essays with Answers (Collegeville: Liturgical Press, 2016).

${ }^{35}$ Francis og Wolton, A Future of Faith: the Path of Change in Politics and Society, 93.

${ }^{36} \S 99-100$. Pope Francis, «Querida Amazonia,»

http://www.vatican.va/content/francesco/en/apost_exhortations/documents/papa-francesco_esortazioneap_20200202_querida-amazonia.html.

${ }^{37}$ Vance-Trembath, "Women and Vatican II. Theological Excavations and Soundings,».

${ }^{38}$ Agnieszka Graff, “'Gender Ideology': Weak Concepts, Powerful Politics,» Religion \& gender 2016, no. 2 (2016): 268.

39 Javier Corrales, «Understanding the Uneven Spread of LGBT rights in Latin America and the Caribbean, 1999 2013," Journal of Research in Gender Studies 7, no. 1 (2017).

40 Jair Messias Bolsonaro, «Discurso do Presidente da República, Jair Bolsonaro, durante Cerimônia de Posse no Congresso Nacional," http://www2.planalto.gov.br/acompanhe-o-planalto/discursos/2019/discurso-dopresidente-da-republica-jair-bolsonaro-durante-cerimonia-de-posse-no-congresso-nacional.

41 José Fernando Serrano Amaya, "La tormenta perfecta: Ideología de género y articulación de públicos,» Sexualidad, Salud y Sociedad. Revista Latinoamericana, no. 27 (2017).

42 Fernanda Marina Feitosa Coelho og Naira Pinheiro dos Santos, «A mobilizacão católica contra a "ideologia de gênero" nas tramiacôes do plano nacional de educâo brasileiro, » Religare 13, no. 1 (2016).

${ }^{43} \mathrm{Av}$ de 180 delegatene var Bergoglio den som fikk suverent flest stemmer for å lede kommisjonen som redigerte sluttdokumentene. Marcelo Larraquy, Código Francisco: cómo el Papa se transformó en el principal líder político global y cuál es su estrategia para cambiar el mundo (Barcelona: Debate, 2016), 323.

${ }^{44}$ The Holy See, "In-flight Press Conference of His Holiness Pope Francis from the Philippines to Rome,» http://www.vatican.va/content/francesco/en/speeches/2015/january/documents/papa-

francesco_20150119_srilanka-filippine-conferenza-stampa.html. «Meeting with the Polish Bishops. Address of his Holiness Pope Francis,"

http://www.vatican.va/content/francesco/en/speeches/2016/july/documents/papa-

francesco_20160727_polonia-vescovi.html; «In-flight Press Conference of His Holiness to Pope Francis from

Azerbaijan to Rome,» 
http://www.vatican.va/content/francesco/en/speeches/2016/october/documents/papafrancesco_20161002_georgia-azerbaijan-conferenza-stampa.html.

${ }^{45} \S 56$ i Pope Francis, «Amoris Laetitia,» https://www.vatican.va/content/dam/francesco/pdf/apost_exhortations/documents/papafrancesco_esortazione-ap_20160319_amoris-laetitia_en.pdf.

${ }^{46}$ Francis og Wolton, A Future of Faith: the Path of Change in Politics and Society, 225.

${ }^{47} \S 56$ i Francis, «Amoris Laetitia».

${ }^{48}$ Fraværet av en kritisk holdningen til androsentrisme er særlig merkbart når encyklikaen kritiserer antroposentrisme. Teresa Toldy, "Someone is Missing in the Common House. The Empty Place of Women in the Encyclical Letter 'Laudatio si',» Journal of the European Society of Women in Theological Research 25(2017): 184.

${ }^{49} \S 155$ i Pave Frans, Encyklikaen Laudato Si'. Om omsorgen for vårt felles hjem, overs. Anne Bente Hadland (Oslo: St. Olav forlag, 2015).

${ }^{50}$ Knut W. Ruyter, «Jorden gråter og de fattige roper,» Kirke og kultur, no. 4 (2020): 308.

${ }^{51}$ Frans, Evangeliets glæde. Apostolsk skrivelse fra pave Frans. 37.

${ }^{52}$ Børresen, «Moderne maktkamp mellom pave og konsil,» 148.

${ }^{53}$ Judith Butler, Kjønn, performativitet og sårbarhet, overs. Lars Holm-Hansen, 1. utgave, Cappelens upopulære skrifter (Oslo: Cappelen Damm, 2020), 51.

${ }^{54}$ Det andre vatikankonsilet, «Pastoralkonstitusjon om Kirken i verden av i dag - Gaudium et spes, i Det Annet vatikankonsil : dokumenter, red. Fredrik Hansen (Oslo: St. Olav forlag, 2013), 503. 